\title{
Analysis of Heat and Smoke Flow according to Platform Screen Door and Fan Conditions on Fire in Underground Platform
}

\author{
Ju-Yeong Jung $\mathbb{D}^{1},{ }^{1}$ Seung-Gu Kang, ${ }^{2}$ Hyuk-Jin Yoon $\mathbb{D}^{3},{ }^{3}$ Kwang-Bok Shin, ${ }^{2}$ \\ and Jong-Kwang Lee $\mathbb{B}^{2}$ \\ ${ }^{1}$ Korea Railroad Research Institute, Uiwang-si 16105, Republic of Korea \\ ${ }^{2}$ Department of Mechanical Engineering, Hanbat National University, 125 Dongseodaero, Yuseong-gu, \\ Daejeon, Republic of Korea \\ ${ }^{3}$ Korea Railroad Research Institute, University of Science and Technology, Uiwang-si 16105, Republic of Korea
}

Correspondence should be addressed to Jong-Kwang Lee; jongkwang@hanbat.ac.kr

Received 16 October 2017; Accepted 16 April 2018; Published 30 May 2018

Academic Editor: Flavio Stochino

Copyright ( 2018 Ju-Yeong Jung et al. This is an open access article distributed under the Creative Commons Attribution License, which permits unrestricted use, distribution, and reproduction in any medium, provided the original work is properly cited.

In this study, a three-dimensional flow analysis of underground subway station was conducted by applying ventilation mode in operation and platform screen door (PSD) opening and closing conditions on fire in underground platform. In order to analyze optimal smoke control and heat removal conditions, the whole underground subway station was set as a model, and a total of eight cases were analyzed by changing the operating conditions of fans for each area under the opening and closing conditions of the PSDs. The analysis results confirmed that the operation mode of supply fan in platform E and I areas located at the third floor underground is more effective than that of exhaust fan in the event of a fire in underground subway station when the PSD is closed. The amount of $\mathrm{CO}$ entering a waiting room increased, and the overall $\mathrm{CO}$ distribution in the underground subway station was also increased when the PSD is opened. In addition, the CO distributions due to the opening and closing of the PSD were similar to one another when a fire occurred on the platform, which suggests that the operating conditions of the fan affects the formation of CO distribution in the underground subway station rather than the discharge of $\mathrm{CO}$.

\section{Introduction}

With the increased traffic volume and diversified transportation services due to the development of industrial society, the seriousness of traffic congestion has already led to problems throughout the society. To solve these problems, various attempts such as the construction of roads and railways have been made to secure land transportation, but it is difficult to overcome the topographical constraints of mountainous terrain in Korea. In addition, traffic noise generated from driving vehicles leads to a problem in the surrounding residential environment. For this reason, a means of transportation in modern society has been developed into the convenient and safe means to meet the demand of passengers, and the typical example includes the use of urban underground space such as subways and tunnels [1].
Subways which are widely used in urban areas are generally safe. However, underground space fire is highly dangerous due to the expanded combustion caused by pipe insulation covers, communication lines, and various pipes installed inside, and it has a characteristic that a large amount of toxic gas is emitted. In addition, the spatial limitations of underground facilities make it almost impossible for firefighters to enter the fire scene, so it takes considerable time to extinguish the fire. In this regard, an accurate prediction of airflow characteristics, temperatures, and smoke concentrations in case of fire is very important in the design of fire extinguishing and prevention systems in underground facilities [2]. In fact, site investigations and reports on survey results reveal that Daegu subway fire disaster that occurred in February 2003, which killed about 200 people, caused more casualties due to the problems of ventilation and smoke control systems in the underground 
subway station. In addition, the contaminated air and dust generated when the vehicle enters the subway station adversely affects the health of passengers as well as crew members.

The PSD (platform screen door) separates the main line from the platform to cut off harmful toxic gases and hightemperature smoke and heat in the event of a fire, provides a safe escape route in an emergency, and reduces unpleasant train-induced wind, dust, and noise coming from the tracks, thereby increasing the air-conditioning efficiency [3-5]. Due to these advantages, the PSD installation is specified as a platform safety facility in the construction of urban railways, and the PSD-related studies have been conducted by many researchers. Lee and Hur [6] numerically analyzed the Daegu subway fire that broke out in 2003 through a 3-D CFD (computational fluid dynamics) simulation. The influence of train-induced wind on the overall fire behavior was analyzed considering the movement of the train entering the subway station from the tunnel, and the flow of smoke and CO concentrations in the underground subway station with time were also analyzed. Jang et al. [7, 8] conducted a basic study on the characteristics of fire propagation due to the presence of the PSD in case of urban railway fire and the validity of the operation mode of the platform ventilation system at deep underground subway station in case of platform fire. Kwon et al. [9] performed a numerical analysis to improve ventilation efficiency by installing an exhaust fan in the lower space of the staircase and thus to solve the problem of deterioration of the ventilation efficiency in the station by removing the influence of the train-induced wind due to the installation of the PSD. Hu et al. [10] analyzed the most effective ventilation mode when a fire occurs on a train between the underground subway platforms by using CFD. Roh et al. [11] investigated the effects of the PSD on the escape time of passengers in the event of fire by using FDS (fire dynamics simulator) code. Park et al. [12] performed an analysis on the heat, smoke, various gases, and visibility under two different exhaust capacities in case of fire by using a numerical analysis, and they experimentally measured major input values such as velocity at various points of a platform and flow rate at over/under platform extracts and air-vents and then used them for calculation in order to increase the accuracy of analysis. Wang and $\mathrm{Li}$ [13] carried out a method to simulate unorganized ventilation in a subway station and verified the accuracy of the simulation method through a field test. They analyzed the air tightness performance of PSD, tunnel length, and train arrival time intervals and used the PSD resistance coefficients as a key input parameter of the simulation. Meng et al. [14] carried out the CFD simulations using fire dynamics simulator (FDS) to examine the effectiveness of different ventilation modes in case of a train fire in a subway station. The subway station with full-seal PSD and half-height safety door was selected to compare the performance of various ventilation modes. $\mathrm{Li}$ and $\mathrm{Zu}$ [15] studied the effects of open mode of platform screen doors on mechanical smoke exhaust in subway station fire using FDS. And the results indicate that the open PSDs on both sides of the platform can reduce the gas temperature and improve the efficiency of mechanical smoke exhaust. Zhu et al. [16] investigated the subway train head fire in the upstream section of the river-crossing tunnel. They used the STESS and CFD software to simulate the ventilation velocity with different patterns, the influence of ventilation velocity on the distribution, temperature, and so on. And the results show that the opening and closing of the PSDs in the direction of personnel escape has a great influence on the ventilation velocity of the tunnel.

As described above, many previous studies have actively been conducted regarding smoke control, heat removal and ventilation methods for underground tracks and platforms. However, all of the existing studies did not take into account the complex ventilation mode which is being operated in the actual underground subway station. In this paper, a CFD analysis of actual underground subway station was conducted to solve the shortcomings of the aforementioned studies, and a flow analysis was performed by applying the ventilation mode operating in the actual underground subway station when a fire occurs in the underground platform. In addition, the opening and closing conditions of the PSD were added to each ventilation mode for case diversification, and heat and smoke flow were analyzed according to the ventilation mode and PSD conditions of underground subway stations.

\section{Numerical Analysis for Underground Subway Station}

\subsection{Analysis Model}

2.1.1. Analysis Area Settings. In this study, the uncompleted subway station of Busan Subway Line 1 was selected as an analysis model. As shown in Figure 1, the underground subway station is about $210 \mathrm{~m}$ in length, about $90 \mathrm{~m}$ in height, and about $27 \mathrm{~m}$ in width and has side platforms. There is a waiting room on the first floor underground, and platforms and mainline tracks are located on the third floor underground. Both floors are connected to the central stairs on the second floor underground. In the actual structure of the underground station, there is a machine room on the second floor underground, but it is a space where passengers do not make visits. Therefore, in this study, only the staircase was designed to simplify the analysis and reduce the calculation load. The third floor underground in which platforms and mainline tracks are located is the place where a fire occurs in the flow calculation, and the PSD exists between the platform and the mainline track. The structures inside the underground subway station that have little effect on the analysis results were excluded or simplified in the design. There are exhaust fans and air supply fans on the ceilings of platform and mainline track in the third floor underground, and a heat source of $1 / 3$ size car and an emergence exist in the platform. On the ceilings of the waiting room from on the first floor underground, an air supply fan is installed, and there is an exit toward the outside of the underground subway station.

In the analysis area, meshing operation was performed using Gambit, a commercial code for preprocessing as 


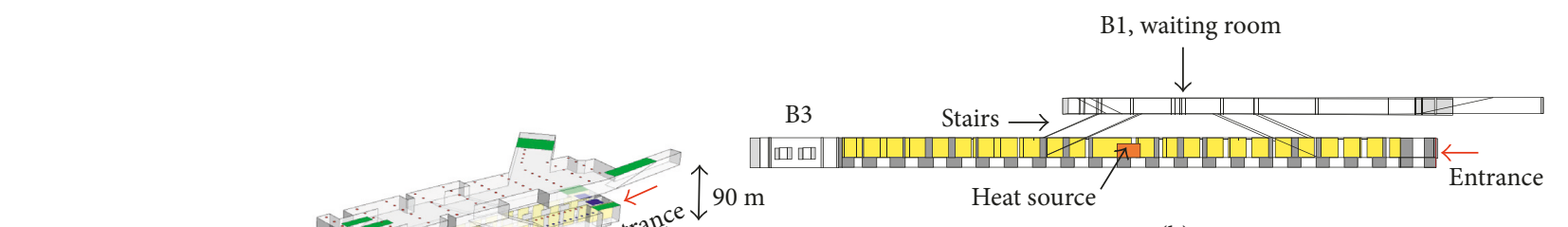

(b)

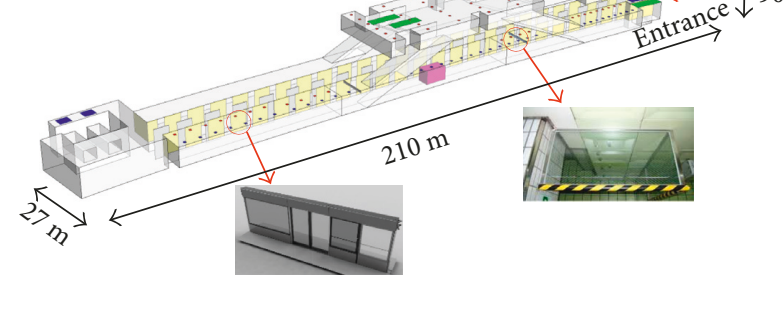

Supply fan Exhaust fan PSD (platform screen door)

$$
\begin{aligned}
& 5 \text { MW heat source } \\
& \text { Exit }
\end{aligned}
$$

(a)

Figure 1: Underground subway station for 3D numerical simulation. (a) Underground subway station. (b) Side view. (c) Top view.

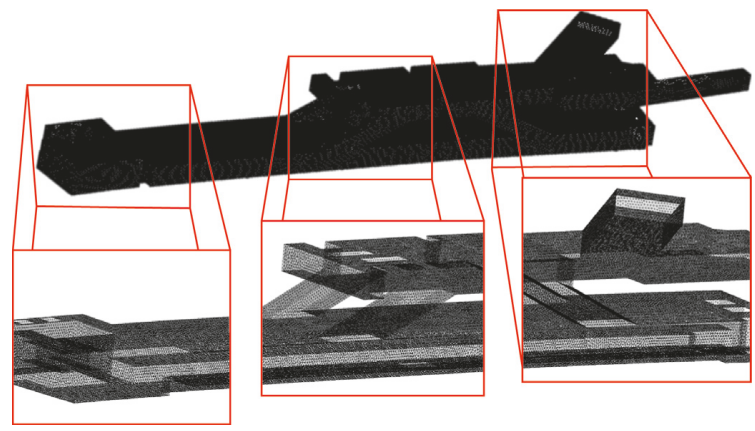

(a)

(a)

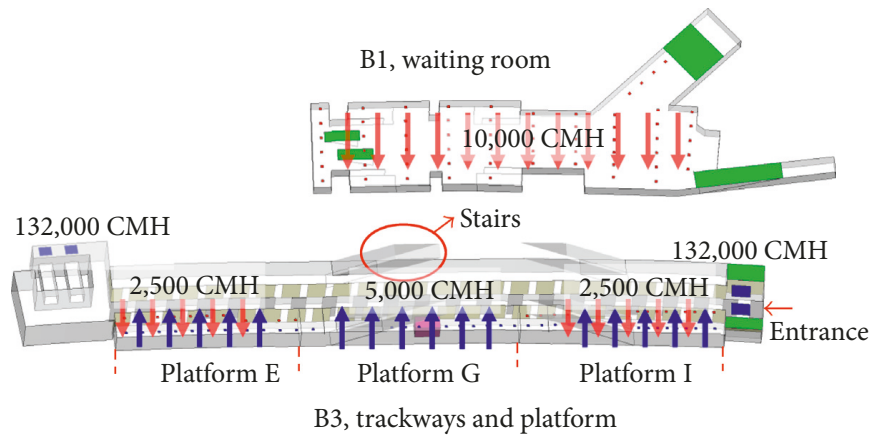

Supply fan

Exhaust fan

PSD

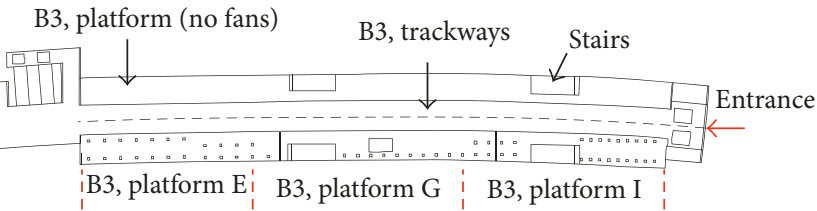

(c)

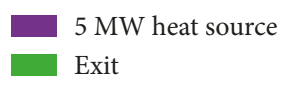

(b)

Figure 2: Mesh model, boundary conditions, and ventilation system. (a) Mesh model. (b) Boundary conditions and ventilation system.

shown in Figure 2(a). Tetrahedral meshes were used in consideration of the shape and internal space of the underground subway station. Three analysis models with $1.5,2$, and 3 million element meshes were used for checking the grid independence. The standard deviation of the CFD results according to the mesh increase was within $0.001 \%$. So the model with 1.5 million element meshes was used to reduce the time cost and the computational load.

2.1.2. Boundary Conditions and Analysis Methods. The boundary conditions applied to the analysis space are shown in Figure 2(b). As the boundary conditions of the third floor underground in which mainline tracks and platform are located, the two largest exhaust fans with a performance of
$132,000 \mathrm{CMH}$ are installed at both ends of the tracks, and 11 exhaust fans are operated at a performance of 5,000 $\mathrm{CMH}$ in $G$ area where a fire occurs. In addition, supply fans and exhaust fans operate according to the operating conditions of fans in $\mathrm{E}$ and I areas on both sides of the fire zone, and the performance of the fan is 2,500 CMH per area. There is an emergence evacuation route at the right end of the track, and the wind is blowing at $2.5 \mathrm{~m} / \mathrm{s}$ at the entrance. In addition, $23 \mathrm{~kg} / \mathrm{s}$ was applied as the CO generation of the $5 \mathrm{MW}$ heat source of the platform in $\mathrm{G}$ area based on the National Fire Safety Code 603 in Korea. In the waiting room on the first floor underground, there are supply fans and an exit toward the outside of the underground subway station. There are a total of 61 fans on the first floor underground, which have the total performance of $10,000 \mathrm{CMH}$. In addition, it was 
TABLE 1: PSD and fan conditions.

\begin{tabular}{|c|c|c|c|c|c|c|}
\hline \multirow{2}{*}{ PSD } & \multirow{2}{*}{\multicolumn{2}{|c|}{ Inlet velocity $(\mathrm{m} / \mathrm{s})$}} & \multicolumn{3}{|c|}{ B3, fan condition } & \multirow{2}{*}{$\begin{array}{c}\text { B1, fan condition } \\
\text { Waiting room }\end{array}$} \\
\hline & & & Platform E & Platform G (fire) & Platform I & \\
\hline \multirow{4}{*}{ Close } & \multirow{4}{*}{2.5} & Case 1 & Air supply & Exhaust & Air supply & Air supply \\
\hline & & Case 2 & Air supply & Exhaust & Air supply & None \\
\hline & & Case 3 & Exhaust & Exhaust & Exhaust & Air supply \\
\hline & & Case 4 & Exhaust & Exhaust & Exhaust & None \\
\hline \multirow{4}{*}{ Open } & \multirow{4}{*}{2.5} & Case 5 & Air supply & Exhaust & Air supply & Air supply \\
\hline & & Case 6 & Air supply & Exhaust & Air supply & None \\
\hline & & Case 7 & Exhaust & Exhaust & Exhaust & Air supply \\
\hline & & Case 8 & Exhaust & Exhaust & Exhaust & None \\
\hline
\end{tabular}

assumed that there are no air inflows and outflows in places other than the fans and the entrance described above.

The flow analysis was performed by using ANSYS Fluent 13.0 which has been verified in this field among various commercial programs. In order to conduct the flow analysis in the underground subway station, the flow phenomenon was assumed to be in a steady state and have a incompressible turbulent flow. As a turbulence model, standard $k-\varepsilon$ turbulence model using a wall function method was used not only to reduce the computational load but also to consider the flow obstacles in the underground subway station. In addition, a numerical analysis was performed using governing equations. The governing equations used are mass conservation equation, momentum equation, turbulent flow energy equation, steady state standard $\mathrm{k}-\varepsilon$ turbulence model, and diffusion equation as shown in the following equations:

$$
\begin{aligned}
\frac{\partial}{\partial x_{i}}\left(\rho u_{i}\right)= & 0 \\
\frac{\partial}{\partial x_{i}}\left(\rho u_{i} u_{j}\right)= & -\frac{\partial p}{\partial x_{i}}+\frac{\partial}{\partial x_{j}}\left[\mu\left(\frac{\partial u_{i}}{\partial x_{j}}+\frac{\partial u_{j}}{\partial x_{i}}-\frac{2}{3} \sigma_{i j} \frac{\partial u_{k}}{\partial x_{k}}\right)\right] \\
& +\frac{\partial}{\partial x_{j}}\left(-\rho \overline{u_{i}^{\prime} u_{j}^{\prime}}\right)
\end{aligned}
$$

$$
\frac{\partial}{\partial x_{i}}\left[u_{i}(\rho E+p)\right]=\frac{\partial}{\partial x_{j}}\left[\left(k+\frac{c_{\mathrm{p}} \mu_{\mathrm{t}}}{\mathrm{Pr}_{\mathrm{t}}}\right) \frac{\partial T}{\partial x_{j}}+u_{i}\left(\tau_{i j}\right)_{\mathrm{eff}}\right]+S_{\mathrm{h}}
$$

$$
\begin{aligned}
\frac{\partial}{\partial x_{i}}\left(\rho k u_{i}\right)= & \frac{\partial}{\partial x_{j}}\left[\left(\mu+\frac{\mu_{\mathrm{t}}}{\sigma_{\mathrm{k}}}\right) \frac{\partial k}{\partial x_{j}}\right] \\
& +G_{\mathrm{k}}+G_{\mathrm{b}}-\rho \varepsilon-Y_{\mathrm{M}}, \\
\frac{\partial}{\partial x_{i}}\left(\rho \varepsilon u_{i}\right)= & \frac{\partial}{\partial x_{j}}\left[\left(\mu+\frac{\mu_{\mathrm{t}}}{\sigma_{\varepsilon}}\right) \frac{\partial \varepsilon}{\partial x_{j}}\right]+C_{1 \varepsilon} \\
& +\frac{\varepsilon}{k}\left(G_{\mathrm{k}}-C_{3 \varepsilon} G_{\mathrm{b}}\right)-C_{2 \varepsilon} \rho \frac{\varepsilon^{2}}{k}, \\
\vec{J}_{i}= & -\left(\rho D_{i, \mathrm{~m}}+\frac{\mu_{\mathrm{t}}}{S_{\mathrm{ct}}}\right) \Delta Y_{i}-D_{\mathrm{T}, i} \frac{\Delta T}{T} .
\end{aligned}
$$

As shown in Table 1, the analysis was performed by considering a total of 8 cases. In cases 1 to 4 , the operating conditions of fans were changed with the PSD closed, and in cases 5 to 8 , the operating conditions of fans were changed with the PSD open. The exhaust fan in the $\mathrm{G}$ area where a fire occurs is always in operation, and the temperature and smoke flow characteristics in the underground subway station according to the operating conditions of fans were investigated as shown in Table 1.

2.2. Analysis Results. The temperature and CO distribution of the underground subway station according to each condition were analyzed to investigate the smoke control and heat removal effects depending on the operating conditions of each fan and PSD in the event of a fire. The detailed results are shown in Tables 2 and 3.

2.2.1. Temperature Distribution. If the PSD is closed, a fire that occurs in $G$ area on the third floor underground does not affect the inside of the mainline tracks since the mainline tracks and platforms are completely blocked in cases 1 to 4 . As shown in Table 1, the operating conditions of fans in the platform on the third floor underground are the same in cases 1 and 2, and the exhaust fans in the platform are in operation in cases 3 and 4 . A look at the average temperature in the platform on the third floor underground (E, G, and I areas) with the PSD closed revealed that the greatest heat removal effect was obtained under the condition of case 1 $(317 \mathrm{~K})$ while the supply fans in the waiting room on the first floor underground and $\mathrm{E}$ and I areas on the third floor underground were in operation, and the average temperatures in the waiting room on the first floor underground were similar to one another $(307-309 \mathrm{~K})$ in cases 1 to 4 .

When the PSD is opened (cases 5 to 8 ), the temperature distribution in the platforms (E, G, and I areas) on the third floor underground was lower than that when the PSD is closed because the heat transfer occurred in the entire area of the third floor underground. The waiting room on the first floor underground showed higher temperature distribution than cases 1 to 4 because the heat energy distributed in the entire area of the third floor underground was introduced into the first floor underground. The average temperatures in the platforms (E, G, and I areas) on the third floor underground of cases 5 to 8 ranged from 308 to $311 \mathrm{~K}$, and the average temperature in the waiting room on the first floor 
TABLE 2: Temperature distribution of the underground subway station.

\begin{tabular}{|c|c|c|c|c|c|c|}
\hline \multirow{2}{*}{ PSD } & & \multicolumn{5}{|c|}{ Mean temperature $(\mathrm{K})$} \\
\hline & & $\mathrm{B} 3$, platform $\mathrm{E}$ & B3, platform G (fire) & B3, platform I & B3, platforms E, G, I & B1, waiting room \\
\hline \multirow{4}{*}{ Close } & Case 1 & 308 & 323 & 318 & 317 & 309 \\
\hline & Case 2 & 328 & 332 & 315 & 325 & 307 \\
\hline & Case 3 & 341 & 344 & 328 & 338 & 308 \\
\hline & Case 4 & 333 & 334 & 319 & 328 & 308 \\
\hline \multirow{4}{*}{ Open } & Case 5 & 305 & 313 & 315 & 311 & 320 \\
\hline & Case 6 & 311 & 311 & 312 & 311 & 320 \\
\hline & Case 7 & 302 & 314 & 309 & 309 & 320 \\
\hline & Case 8 & 299 & 314 & 310 & 308 & 320 \\
\hline
\end{tabular}

TABLE 3: CO distribution of the underground subway station at the height of $1.6 \mathrm{~m}$.

\begin{tabular}{|c|c|c|c|c|c|c|c|}
\hline \multirow{2}{*}{ PSD } & & \multicolumn{6}{|c|}{$\mathrm{CO}$ distribution at the height of $1.6 \mathrm{~m}(\%)$} \\
\hline & & B3, platform E & B3, platform G (fire) & B3, platform I & B3, platforms E, G, I & B1, waiting room & Subway station \\
\hline \multirow{4}{*}{ Close } & Case 1 & 6 & 12.2 & 9.3 & 9.3 & 5.2 & 4.7 \\
\hline & Case 2 & 17.7 & 15.8 & 6.9 & 13.2 & 4.6 & 3.9 \\
\hline & Case 3 & 27.7 & 25 & 17.2 & 23 & 4.3 & 5 \\
\hline & Case 4 & 21.6 & 18.6 & 10.9 & 16.7 & 4.8 & 4.2 \\
\hline \multirow{4}{*}{ Open } & Case 5 & 2.6 & 6.7 & 7.8 & 5.9 & 10.5 & 8.1 \\
\hline & Case 6 & 5.5 & 5.8 & 6.3 & 5.9 & 10.2 & 8 \\
\hline & Case 7 & 8.6 & 13.9 & 9.9 & 10.9 & 10.7 & 7.7 \\
\hline & Case 8 & 0.3 & 7.2 & 5.5 & 4.6 & 10.3 & 9 \\
\hline
\end{tabular}

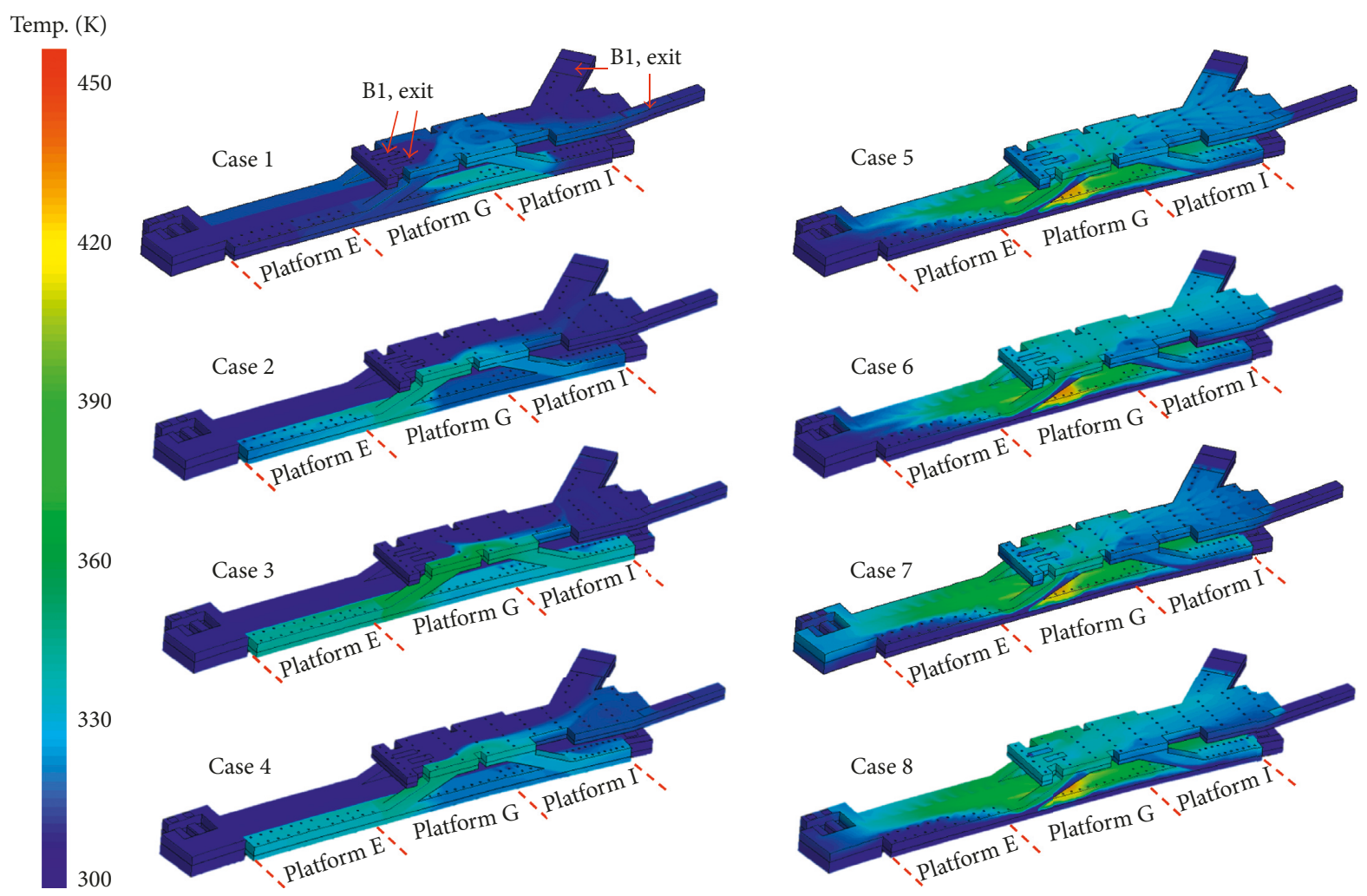

Figure 3: Temperature contours of underground subway station.

underground was $320 \mathrm{~K}$. Figure 3 shows the temperature distributions of the underground subway station according to each case, and the temperature distribution results were compared in detail as shown in Table 2.
2.2.2. CO Distribution. The results of CO distribution were analyzed under the assumption that the breathing height of passengers is $1.6 \mathrm{~m}$. As in the case of the temperature distribution, the conditions of case 1 showed the greatest smoke 

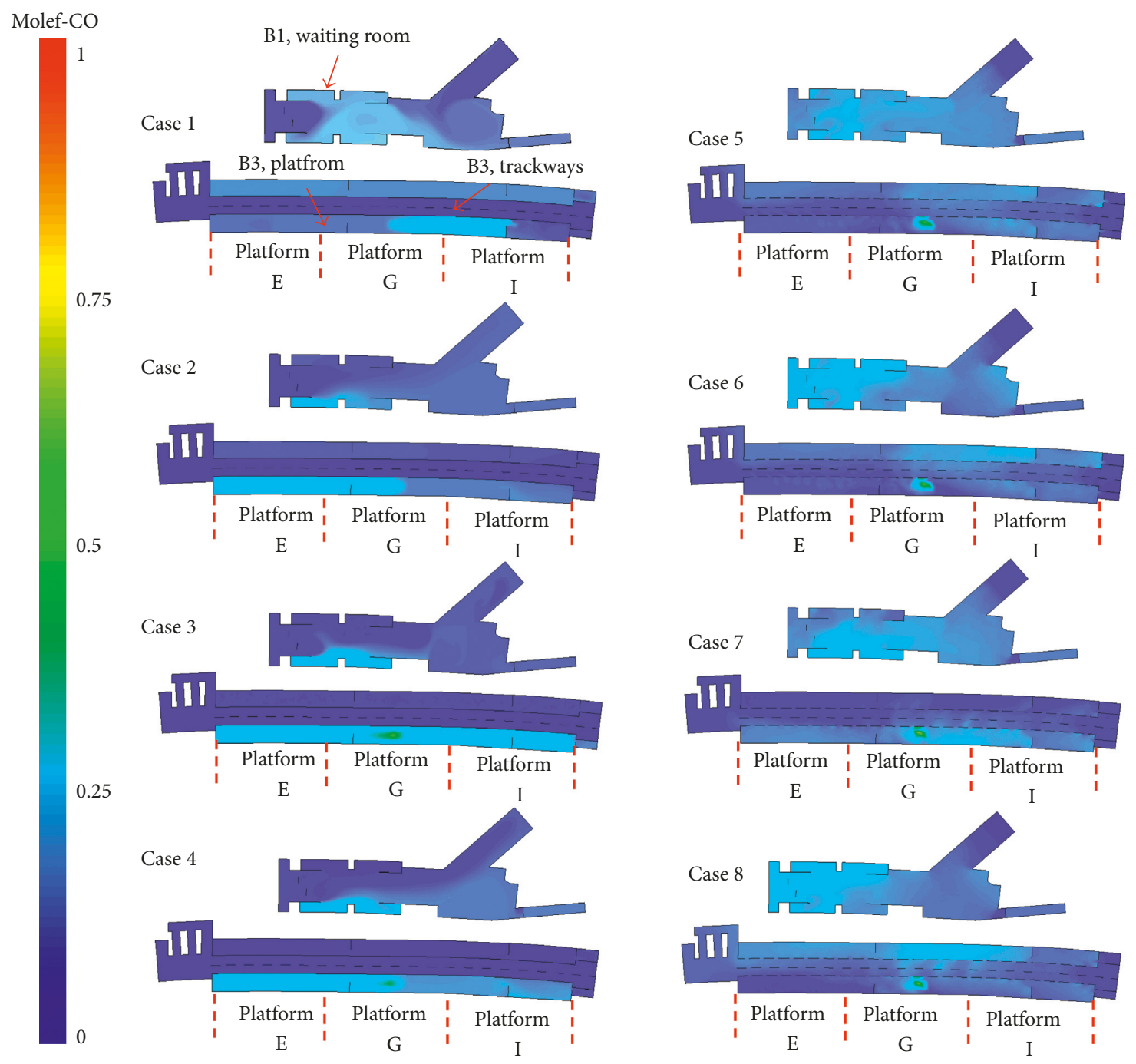

Figure 4: CO contours of underground subway station at the height of $1.6 \mathrm{~m}$.

control effect of $9.3 \%$ in CO distribution with the PSD closed in the platforms (E, G, and I areas) on the third floor underground. The CO distribution of case 2 was $3.2 \%$, and cases 3 and 4 showed results of $23 \%$ and $16.7 \%$, respectively. In addition, the $\mathrm{CO}$ distribution in the waiting room on the first floor underground ranged from 4.3 to $5.2 \%$ in cases 1 to 4 and that of the entire underground subway station also showed the similar results of 3.9 to $5 \%$.

When the PSD is opened, the CO distribution in the platforms (E, G, and I areas) on the third floor underground showed that the lowest efficiency of $10.9 \%$ was found in case 7 , and cases 5,6 , and 8 also showed similar distributions ranging from 4.6 to $5.9 \%$. However, when the CO distributions on the first floor underground and in the entire underground subway station were checked, the CO distribution was similar in each result according to the status (open and close) of the PSD. This suggests that the operating conditions of the fans in the event of a fire in the underground subway station have a greater influence on the formation of $\mathrm{CO}$ distribution than on the discharge of $\mathrm{CO}$.
The detailed results of $\mathrm{CO}$ distribution in the underground subway station are shown in Table 3, and Figures 4 and 5 show CO distributions measured at a breathing height of $1.6 \mathrm{~m}$.

2.2.3. Comparison of Analysis Results according to the PSD Conditions. When the PSD is closed, the greatest smoke and heat removal effect was obtained from the platforms on the third floor underground of case 1 where supply fans in the waiting room and $\mathrm{E}$ and I areas on the third floor underground were in operation. On the other hand, three cases except for case 7 showed similar results when the PSD is opened. In addition, the analysis results of 8 cases confirmed that case 3 where exhaust fans on the third floor underground and supply fans in the waiting room were in operation with the PSD closed has the condition that demonstrates the lowest level of smoke and heat removal efficiency in the event of a fire. However, the changes in temperatures and $\mathrm{CO}$ distributions in the underground 

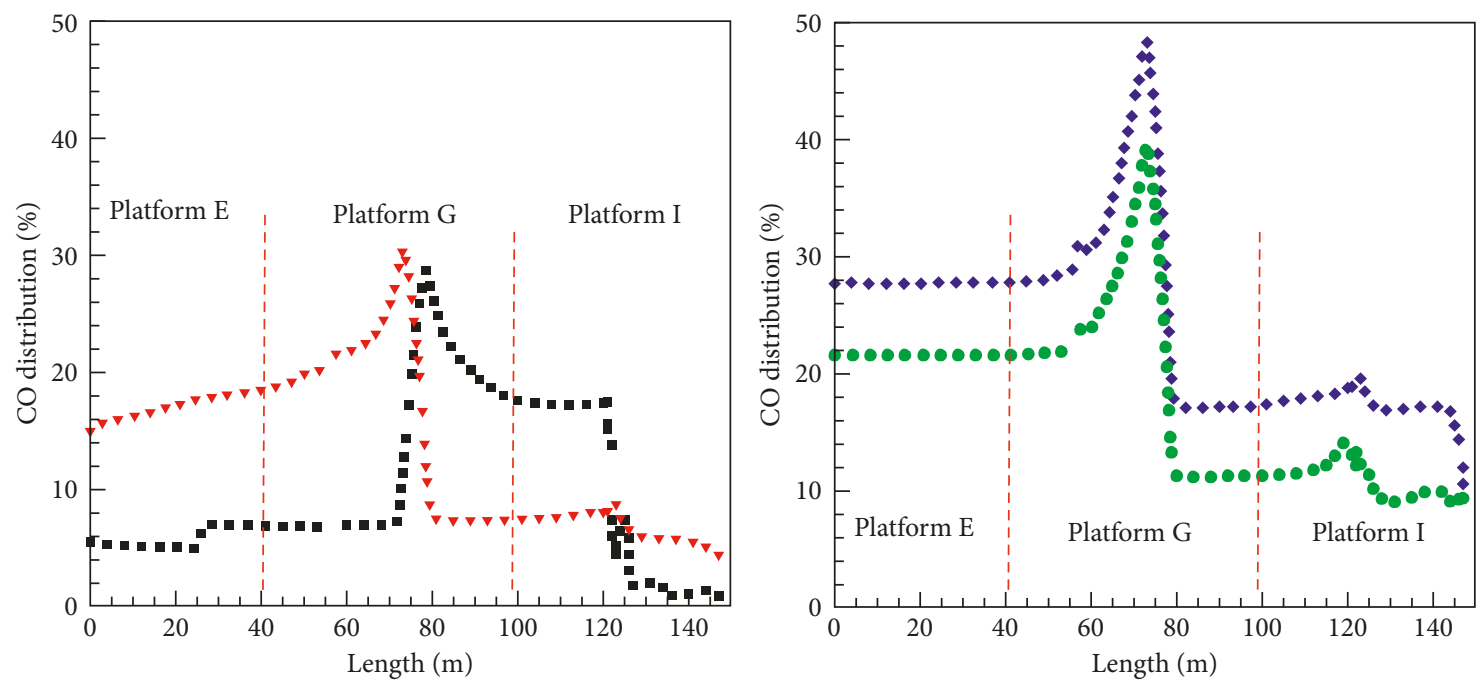

- Case 1

$\checkmark$ Case 2

- Case 3

- Case 4

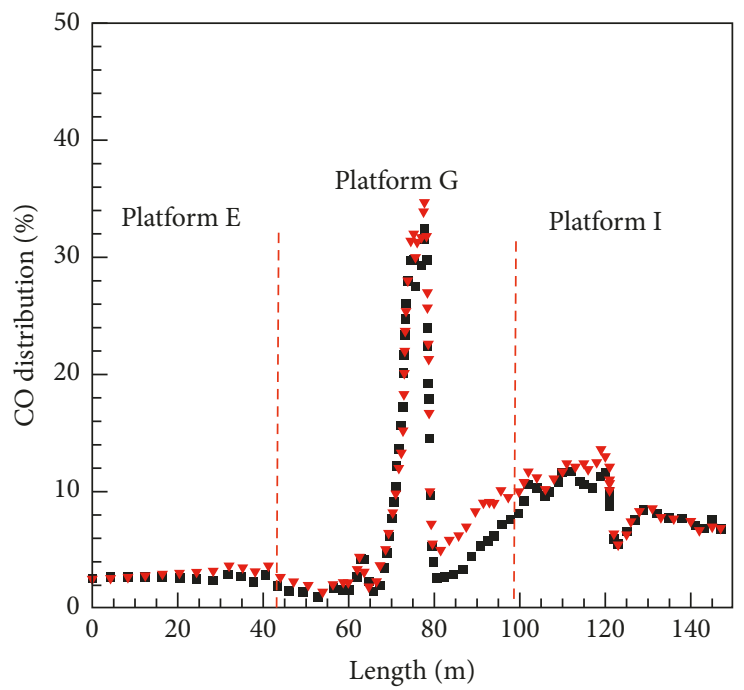

- Case 5

$\checkmark$ Case 6

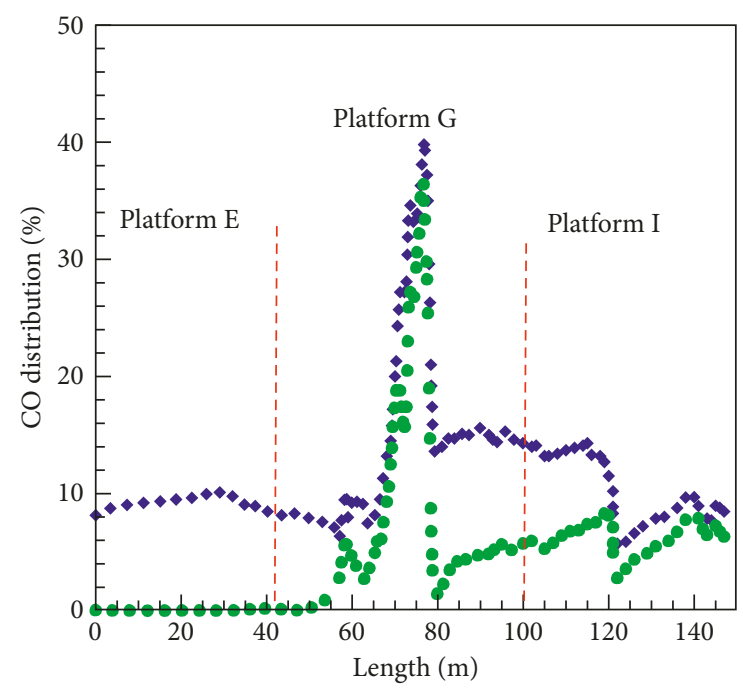

- Case 7

- Case 8

Figure 5: CO distributions of platforms E, G, and I at the height of $1.6 \mathrm{~m}$.

subway station according to the operating conditions of the PSD and fans indicate that the flow of toxic gas and heat caused by fire can be controlled. Therefore, it is expected that all the analysis conditions performed in this paper can demonstrate the optimal smoke control and heat removal effects depending on the situation.

\section{Summary and Conclusion}

In this study, a three-dimensional heat flow analysis was performed by applying the ventilation mode operating in the actual underground subway station and the status (open and close) of the PSD in the event of a fire on the platform at the underground subway station. In the analysis, the entire underground subway station was set as the calculation area, and the analysis was conducted regarding 8 cases. The following conclusions were obtained based on the results.
When the PSD is closed, operation mode of supply fans of platforms E and I was more effective in smoke control and heat removal than that of exhaust fans in the event of a fire. And when the PSD is opened, the CO distributions according to the operation mode of fans showed similar results, and the smoke removal efficiency of the platform on the third floor was improved. However, the amount of $\mathrm{CO}$ flowing into the waiting room increased, and thus the overall $\mathrm{CO}$ distribution in the underground subway station also increased. The results according to the status (open and close) of the PSD showed that CO distributions were similar, which suggests that the operating conditions of fans affect the formation of $\mathrm{CO}$ distribution rather than the discharge of CO. Finally, the analysis results showed that the flow of heat and harmful gas can be controlled by the operating conditions of the fans and the PSD in the underground subway station. Therefore, it is expected that the analysis 
conditions performed in this paper can demonstrate optimal smoke control and heat removal effects depending on the fire situation. Based on the analysis results, it is possible to devise appropriate rescue plans for each particular situation, such as setting fire suppression paths, securing evacuation routes, and preventing the spread of smoke or toxic gases to help passengers to breathe in the event of a fire in the underground subway station. In addition, the findings of this study are expected to be used as basic data for the design of new smoke control and heat removal systems.

\section{Nomenclature}

\begin{tabular}{ll}
$\rho:$ & Fluid density \\
$u:$ & Velocity vector \\
$p:$ & Pressure \\
$\mu:$ & Fluid viscosity \\
$\delta_{i j}:$ & Kronecker delta \\
\hline$u_{i}^{\prime} u_{j}^{\prime}:$ & Average of the turbulent fluctuation \\
$E:$ & Total energy \\
$k:$ & Thermal conductivity (3), turbulence \\
$c_{\mathrm{p}}:$ & kinetic energy $(4)$ \\
$\mathrm{Pr}:$ & Heat capacity \\
$T:$ & Turbulent Prandtl number \\
$\left(\tau_{i j}\right)_{\mathrm{eff}}:$ & Static temperature \\
$G_{\mathrm{k}}:$ & Viscous stress tensor \\
$G_{\mathrm{b}}:$ & Generation of turbulence kinetic energy \\
$\varepsilon:$ & due to mean velocity gradients \\
$Y_{\mathrm{M}}:$ & Generation of turbulence kinetic energy \\
$C_{i \varepsilon} ; i=1,2$, & due to buoyancy \\
$\vec{J}_{i}:$ & Rate of dissipation \\
$D_{i, \mathrm{~m}}:$ & Contribution of the fluctuating dilatation \\
$S c_{\mathrm{t}}:$ & Diffusion flux of species $i$ \\
$\mu_{\mathrm{t}}:$ & Mass diffusion coefficient for species $i$ \\
$D_{\mathrm{t}}:$ & Turbulent Schmidt number \\
$D_{\mathrm{T}, i}:$ & Turbulent viscosity \\
& Turbulent diffusivity \\
& Thermal diffusion coefficient.
\end{tabular}

\section{Disclosure}

An earlier version of this work was presented at Autumn Conference and Annual Meeting of the Korean Society for Railway, 2016.

\section{Conflicts of Interest}

The authors declare that there are no conflicts of interest regarding the publication of this paper.

\section{Acknowledgments}

This research was supported by a grant from R\&D Program of the Korea Railroad Research Institute, Republic of Korea.

\section{References}

[1] J. Ju-Yeong, K. Seung-Gu, Y. Hyuk-Jin, S. K. Bok, and L. JongKwang, "Analysis of heat and smoke flow according to platform screen door and fan conditions on fire in underground platform," in Proceedings of the Korean Society for Railway Conference, pp. 406-412, Jeju Island, Korea, 2016.

[2] K. C. Lee et al., "A numerical study of fire in a long longitudinal tunnel with natural ventilations," in Proceedings of the Korean Institute of Fire Science and Engineering Conference, Korean Institute of Fire Science and Engineering, pp. 272-280, Gangwon-do, Korea, 2005.

[3] S.-B. Kwon, H.-G. Namgung, W. Jeong, D. Park, and J. K. Eom, "Transient variation of aerosol size distribution in an underground subway station," Environmental Monitoring and Assessment, vol. 188, no. 6, p. 362, 2016.

[4] T.-J. Lee, J.-S. Jeon, S.-D. Kim, and D.-S. Kim, “A comparative study on PM 10 source contributions in a Seoul metropolitan subway station before/after installing platform screen doors," Journal of Korean Society for Atmospheric Environment, vol. 26, no. 5, pp. 543-553, 2010.

[5] J.-S. Jeon, J.-C. Yoon, H.-C. Lee, S.-W. Eom, and Y.-Z. Chae, "A noticeable change in indoor radon levels after platform screen doors installation in Seoul subway station," Journal of Korean Society for Atmospheric Environment, vol. 28, no. 1, pp. 59-67, 2012.

[6] M. Lee and N. Hur, "CFD simulation of 2003 Daegu metro fire," in Proceedings of the SAREK, pp. 841-844, Gangwon-do, Korea, 2011.

[7] Y. J. Jang et al., "Effect of platform screen door on fire in the subway station," in Proceedings of the Korean Society for Railway Conference, pp. 1331-1339, Gyeonggi-do, Korea, 2007.

[8] Y. J. Jang and J.-M. Ryu, "Investigation of ventilation operation modes for platform fire in subway station," Korean Society for Railway, pp. 104-109, Gangwon-do, Korea, 2013.

[9] S.-B. Kwon, J.-H. Song, J.-H. Ryu et al., "A study on the improvement of the air exhaust system at the PSD installed subway station," Journal of Korean Tunnelling and Underground Space Association, vol. 17, no. 3, pp. 353-362, 2015.

[10] L. Hu, L. Wu, K. Lu, X. Zhang, S. Liu, and Z. Qiu, "Optimization of emergency ventilation mode for a train on fire stopping beside platform of a metro station," Building Simulation, vol. 7, no. 2, pp. 137-146, 2014.

[11] J. S. Roh, H. S. Ryou, W. H. Park, and Y. J. Jang, "CFD simulation and assessment of life safety in a subway train fire," Tunnelling and Underground Space Technology, vol. 24, no. 4, pp. 447-453, 2009.

[12] W. H. Park, D. H. Kim, and H. C. Chang, "Numerical predictions of smoke movement in a subway station under ventilation," Tunnelling and Underground Space Technology, vol. 21, no. 3, p. 304, 2006.

[13] Y. Wang and X. Li, "Unorganized ventilation in subway stations with platform screen doors," Building and Environment, vol. 125, pp. 556-564, 2017.

[14] N. Meng, L. Hu, L. Wu et al., "Numerical study on the optimization of smoke ventilation mode at the conjunction area between tunnel track and platform in emergency of a train fire at subway station," Tunnelling and Underground Space Technology, vol. 40, pp. 151-159, 2014.

[15] D.-Y. Li and G.-Q. Zhu, "Effect of platform screen doors on mechanical smoke exhaust in subway station fire," Procedia Engineering, vol. 211, pp. 343-352, 2018.

[16] P. Zhu, C. Liu, L. Chen, W. Xu, and J. Mei, "Numerical simulation and measurement of fire ventilation in rivercrossing tunnel," Procedia Engineering, vol. 205, pp. 153159, 2017. 


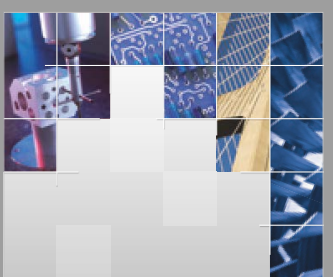

\section{Enfincering}
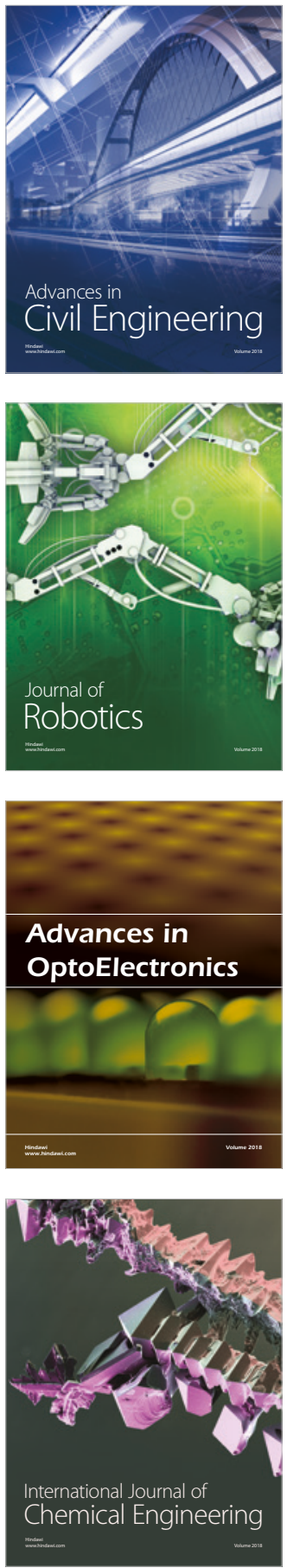

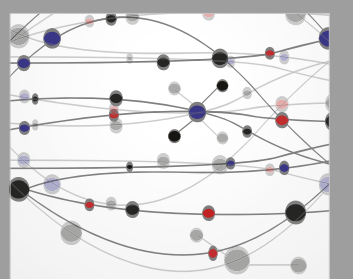

\section{Rotating \\ Machinery}

The Scientific World Journal

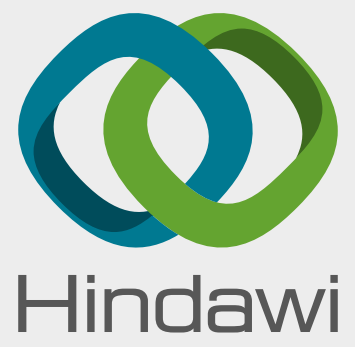

Submit your manuscripts at

www.hindawi.com
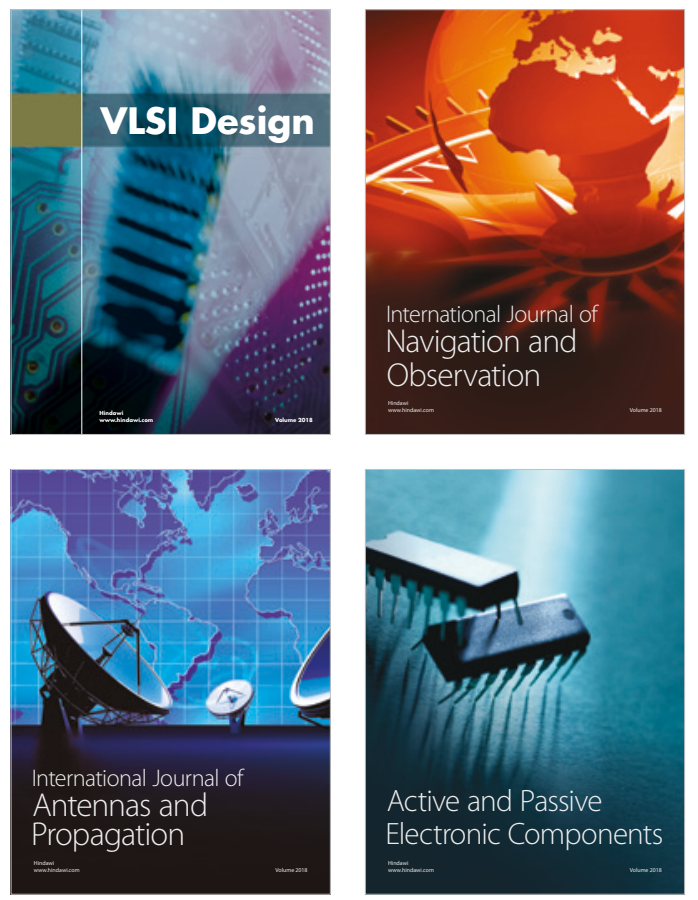
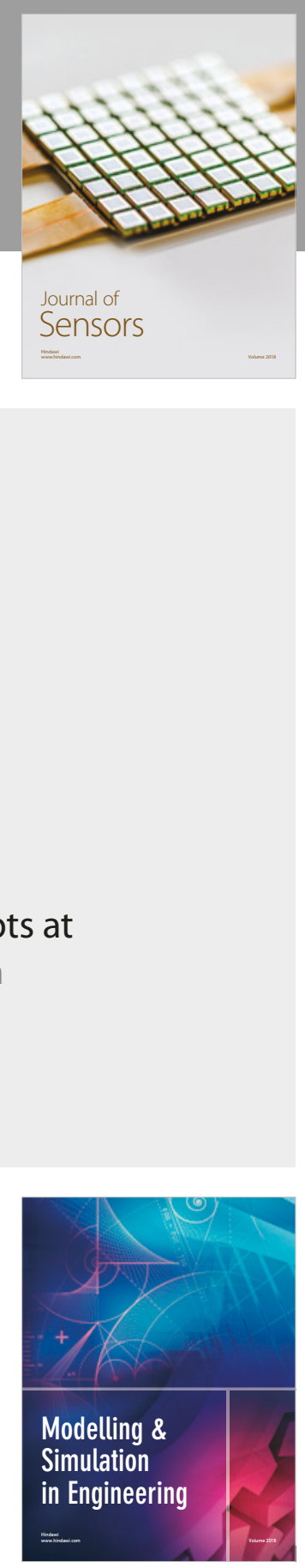

\section{Advances \\ Multimedia}
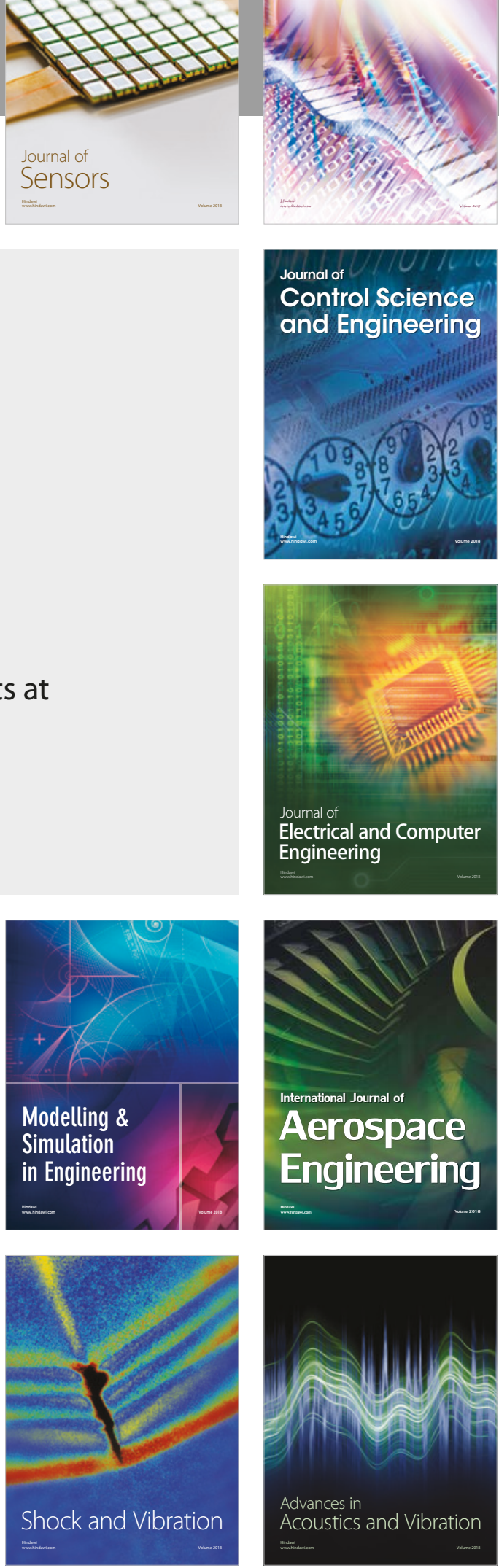